\title{
Phorbol 12-myristate 13-acetate (PMA) Alters Galectin Gene Expression in Cows
}

\author{
Bharath K. Mulakala ${ }^{1} \&$ Mulumebet Worku ${ }^{1}$ \\ ${ }^{1}$ Department of Animal Sciences, North Carolina A\&T State University, 1601 E market street, Greensboro, NC \\ 27411, USA \\ Correspondence: Bharath Kumar Mulakala, Department of Animal Sciences, North Carolina Agricultural and \\ Technical State University, 1601 East Market Street, Greensboro, NC-27411, USA. Tel: 1-336-686-9650. E-mail: \\ bmulakala@aggies.ncat.edu \\ Mulumebet Worku, Department of Animal Sciences, North Carolina Agricultural and Technical State University, \\ 1601 East Market Street, Greensboro, NC-27411, USA. Tel: 1-613-947-3592. E-mail: worku@ ncat.edu
}

Received: March 30, 2021

Accepted: October 19, $2021 \quad$ Online Published: October 29, 2021

doi:10.5539/jmbr.v11n1p1

URL: https://doi.org/10.5539/jmbr.v11n1p1

\begin{abstract}
Galectins (GAL) are $\beta$-galactoside binding proteins. The objective of this study was to assess the effect of PMA on the regulation of galectin gene expression in bovine blood and neutrophils. Blood was collected from 3 clinically healthy Holstein cows. Neutrophils were isolated by differential centrifugation. Blood and neutrophils were treated with $10 \mathrm{ng} / \mathrm{ml}$ of PMA or maintained in phosphate-buffered saline for 30 minutes at $37^{0} \mathrm{C}$. Pooled total RNA were transcribed to cDNA for real-time PCR. Specific primers for bovine LGALS -1, -2, -3, -4, -7, -8 , $-9,-11,-12$, and their binding proteins (bp) LGALS3bp, T cell immunoglobulin and mucin domain 3 (TIM-3) were used. Housekeeping genes RPLP0 and UCHL5 served as internal controls. Fold changes were calculated using the Livak method. Total protein concentration was assessed using the Bicinchoninic acid assay. Secretion of GAL -1, -2, -3, -4, -8, -9 was assessed using bovine GAL specific ELISA. All tested LGALS were detected. Activation with PMA differentially modulated expression and secretion of GAL in blood and neutrophils. Expression levels of LGALS -1 and LGALS -3 was not affected. Expression of LGALS -7, -8, -9, -11, -12, and TIM- 3 was differentially modulated. The secretion of GAL -3 was significantly increased in response to PMA. The most pronounced effect of PMA was observed on LGALS-9, TIM-3 expression, and the secretion of GAL -3. Thus, GAL may serve as biomarkers of cell activation with functional consequences and warrant further study.
\end{abstract}

Keywords: galectins, PMA, neutrophils

\section{Introduction}

Lectin Galactoside-Binding Soluble (LGALS) gene codes for several galectins (GAL). Galectins are a family of animal lectins that typically bind $\beta$-galactoside carbohydrates with high specificity (Modenutti, Capurro, Di Lella, \& Martí, 2019). They are ubiquitously distributed across the mammalian tissues, including the innate and adaptive cells (Stowell et al., 2008), and their differential regulation is essential for maintaining cellular functions (Laderach et al., 2012). Galectins are known to act as pattern recognition receptors and Pathogen Associated Molecular Patterns (PAMPs) that regulate immune responses according to the level of pathogenicity of the invading microorganisms (van Kooyk and Rabinovich, 2008, Sato et al., 2009). Furthermore, their binding proteins, such as Galectin-3 binding protein (LGALS3bp), $\mathrm{T}$ cell Immunoglobulin, and Mucin-domain-containing- protein 3 (TIM-3) play an important role in health and homeostasis. Galectin-3 binding protein is a heavily glycosylated protein that acts as a ligand for GAL-1, $-3,-7$, and promotes cell-cell adhesion through bridging between galectin molecules bound to extracellular components (Sundqvist et al., 2018). Whereas, Tim-3 acts as a ligand for GAL -9 by binding GAL -9 to TIM-3 on immune cells to modulate the inflammatory response to bacteria (Vega-Carrascal et al., 2014). Recent studies have shown that regulation of LGALS gene expression and secretion is part of an effective immune system needed to combat infection and control disease.

Galectins have been studied in cows. Out of the fifteen (15) different LGALS genes that have been identified in mammals, LGALS -1, -2, 3, -4, -7, -8, -9, 11, 12 were expressed in cows (Emmanuel Kwaku Asiamah, 2018; Nio-Kobayashi, 2017; Young, Barcham, McWilliam, Piedrafita, \& Meeusen, 2012). Galectin expression and 
secretion in cow blood and neutrophils have been studied and reported previously (Asiamah et al., 2017; Eluka-Okoludoh, Ekwemalor, Mulakala, Adjei-Fremah, \& Worku, 2019; M Worku et al., 2018). As reported in humans, GAL expression and secretion in cow blood and neutrophils are modulated under physiological pathological and dietary conditions. For instance, LGALS gene expression and secretion are modulated in peripheral cow blood by phenol extract (Adjei-Fremah \& Worku, 2019), diet, periparturient period, stage of lactation, and parity (EK Asiamah, Adjei-Fremah, Ekwemalor, Sordillo, \& Worku, 2018), and with different PAMPS (Emmanuel Kwaku Asiamah et al., 2019). In neutrophils, their expression and secretion were modulated by amino acid supplementation (Emmanuel Kwaku Asiamah, 2018). Further, another recent study has shown that GAL is involved in the modulation of innate and adaptive immunity in bovine neutrophils (Eluka-Okoludoh et al., 2019). Galectin expression and secretion must be tightly regulated to involve in various functions. However, the factors involved in regulating LGALS gene expression and secretion in bovine are still largely unknown.

The innate immune system, primarily leukocytes, serves as the first line of host defense and plays a crucial role in early recognition and pro-inflammatory response (Medzhitov \& Janeway Jr, 2000). Neutrophils play an essential role in the host defenses of cattle against pathogens (Paape, Mehrzad, Zhao, Detilleux, \& Burvenich, 2002). For Instance, mammary gland infection by pathogens is characterized by a rapid influx of neutrophils from blood into the infected glands, where they are responsible for phagocytosing and killing the microbes. As reviewed by (Robinson et al., 2019), galectins appear to influence every aspect of neutrophil's function through their unique sensitivity to oxidative and proteolytic inactivation during inflammation. Further, this review suggested that these proteins may serve as useful pharmacological agents to favorably alter disease states marked by inadequate or exuberant neutrophils function.

Protein kinase C (PKC) forms a key family of enzymes involved in regulating signal transduction pathways important for both innate and adaptive immunity, ultimately resulting in the expression of key immune genes (Lim et al. 2015). Activation of protein kinase $\mathrm{C}$ has been linked to regulation of GAL gene expression (Chabot et al., 2002; Kim, Mayer, \& Nachtigal, 2003; Popa, Stewart, \& Moreau, 2018). Activation of bovine blood and neutrophils involves protein kinases signaling pathways (Adjei-Fremah, Jackai, Schimmel, \& Worku, 2018). Phorbol 12-myristate 13-acetate activates PKC and affects neutrophil NADPH-oxidase activity and secretion of GAL in human cell lines (Karlsson, Nixon, \& McPhail, 2000; Madrigal-Matute et al., 2014). Studies have shown that human and bovine neutrophils respond differently to PMA (Brown \& Roth, 1991). The purpose of this study was to determine the effect of PKC activation on the expression and secretion of galectins by PMA in cow neutrophils and whole blood.

\section{Materials and Methods}

\subsection{Animals and Blood Sampling}

The Institutional Animal Care and Use Committee of North Carolina A\&T State University approved all protocols for animal handling. Three clinically healthy, Holstein-Friesian $(\mathrm{N}=3)$ cows were randomly selected from the North Carolina A\&T State Dairy farm. None of the animals showed any signs of disease or received medications before blood sampling. Fifty milliliters of blood was collected aseptically from the jugular vein of the animals into vacutainer tubes containing $1 \mathrm{~mL}$ of the anti-coagulant Acid Citrate Dextrose.

\subsection{Neutrophil Isolation}

Neutrophils were isolated from whole blood using the modified Carlson and Kaneko method (Carlson \& Kaneko, 1973). Isolated neutrophils, viability, and total cell count were determined on a cell counting instrument (Bio-Rad). The average purity of neutrophil preparations was $94 \%$ or higher, as identified by stained smears. White blood cell differential count was calculated as described previously (Worku et al., 2020; Adjei-Fremah et al., 2016; Ekwemalor et al., 2016).

\subsection{Stimulation of Neutrophils and Whole Blood}

One $\mathrm{mL}$ of neutrophils and whole blood from each cow was incubated with $10 \mathrm{ng} / \mathrm{mL}$ each of either PMA (Sigma- Aldrich St. Louis, MO) or phosphate-buffered saline (PBS). Samples treated with PBS served as control. Samples were incubated at $37^{\circ} \mathrm{C}$ for 30 minutes. At the end of the incubation period, the tubes were spun down at $1700 \mathrm{x} \mathrm{g}$ at $4^{\circ} \mathrm{C}$ for 10 minutes. Neutrophils supernatants and plasma were collected and stored at $-80^{\circ} \mathrm{C}$ until further processing.

\subsection{Blood Cell Analysis}

Blood samples were analyzed for total cell count, viability, and white blood cell differential counts (WBC) following the procedure described by (Emmanuel K Asiamah, Adjei-Fremah, Osei, Ekwemalor, \& Worku, 2016). 
Briefly, total cell count and viability of blood cells before and after PMA treatment were determined in the diluted blood (1:1000 PBS). Diluted samples were mixed with trypan Blue and counts were performed on a cell counting instrument (Bio-Rad, Hercules, CA). To conduct WBC, a thin blood smear was prepared on sterile glass slides in duplicate for each animal. Wright staining was used for histological cell staining.

\subsection{Total RNA Isolation}

Total RNA was isolated using Trizol according to the manufacturer's instructions (Sigma-Aldrich St. Louis, MO). The RNA concentration in nano-gram per microliter ( $\mathrm{ng} / \mu \mathrm{l})$ and purity was assessed using a Nanodrop Spectrometer ND 1000 (Thermo Scientific Inc., Waltham, MA)

\subsection{RT-qPCR Analysis}

Reverse transcription of RNA was performed using Oligo (dT) primers using a cDNA RETRO script Kit (Ambion Inc., Austin, TX). Cow LGALS -1, -2, -3, -4, -7, -8, -9, -11, -12, TIM-3 and LGALS3bp specific primers were used (EK Asiamah et al., 2018). Six candidate reference genes Ribosomal Protein Lateral Stalk Subunit P0 (RPLP0), Ubiquitin C-Terminal Hydrolase L5 (UCHL5), Beta-2-Microglobulin (B2M), Glyceraldehyde 3-phosphate dehydrogenase (GAPDH), TATA-Box Binding Protein (TBP), Beta-actin (ACTB) ) were evaluated (Brym, Ruść, \& Kamiński, 2013; Jarczak, Kaba, \& Bagnicka, 2014) to select appropriate internal controls. By GeNorm Analysis, pair of housekeeping genes that exhibit the lowest $\mathrm{M}$ values served as internal controls (Boissonneault et al., 2013). In our study, RPLP0 and UCHL5 exhibited the lowest M values. Real-time PCR was performed on a CFX Connect system (Bio-Rad Laboratories, CA). The PCR conditions used were the same as reported by (Emmanuel K Asiamah et al., 2016).

\subsection{Evaluation of Total Protein Concentration}

Total protein concentration in supernatant and plasma was measured using the bicinchoninic acid assay (BCA) following the manufacturer's instructions (Thermo Scientific ${ }^{\mathrm{TM}}$ Pierce). A standard curve using known BSA concentrations was used to determine the protein concentration of each unknown sample.

\subsection{Evaluation of Galectin Secretion}

Galectin secretion was assessed in supernatant and plasma using commercially available cow galectin 1, 2, 3, 4, 8, 9 ELISA kits (My BioSource, Inc., San Diego, CA; ABclonal, Woburn, MA) following the manufacture's protocol.

\subsection{Statistical Analyses}

Data were analyzed using SAS software version 9.4 (SAS Institute, Cary, NC). For cell counts, viability, white blood differential cell counts, total protein concentration, and galectin secretion, the means of treatment groups were compared to the control group with one-way Analysis of variance (ANOVA). Real-time PCR data were analyzed using the Livak method. Housekeeping gene RPLP0 and UCHL5 were used for normalization. Fold change in gene expression between test and control samples determined by using the $2^{-\Delta \Delta \mathrm{Ct}}$ methods (Livak \& Schmittgen, 2001). Where $\Delta \Delta \mathrm{Ct}=\Delta \mathrm{Ct}$ (Target genes treat - RPLP0 treat / UCHL5 treat) $-\Delta \mathrm{Ct}$ (Target genes control - RPLP0 control / UCHL5 control). A fold change $>2$ considered as significant. Statistical significance was set at a $\mathrm{P}<0.05$.

\section{Results}

\subsection{Effect of Treatment on Total Cell Count and Viability}

Treatment of whole blood and neutrophils with PMA did not show any significant difference in total cell count and viability compared to the control groups ( $p>0.05$ ) (Table 1 ).

Table 1. Analysis of whole blood and neutrophil in the PMA treated and control group

\begin{tabular}{lllll} 
& Parameter & Control & PMA treated & $P$-value \\
\cline { 2 - 2 } & & & \\
Total cell count (cells $/ \mathrm{ml})$ & $1.5 \times 10^{7} \pm$ & $1.3 \times 10^{7} \pm$ & $\mathrm{NS}$ \\
& Total viable cells (cells/ml) & $4.2 \times 10^{6} \pm$ & $3.8 \times 10^{6} \pm$ & $\mathrm{NS}$ \\
& Neutrophils & & & \\
& Total cell count (cells $/ \mathrm{ml})$ & $8.10 \times 10^{6} \pm$ & $7.23 \times 10^{6} \pm$ & $\mathrm{NS}$ \\
& Total viable cells (cells $/ \mathrm{ml})$ & $1.8 \times 10^{6} \pm$ & $1.7 \times 10^{6} \pm$ & $\mathrm{NS}$ \\
Neutrophils (\%) & $94 \pm 96$ & $95 \pm 96$ & $\mathrm{NS}$ \\
\hline
\end{tabular}

Note. NS $=P>0.05$ 


\subsection{White Blood Cell Differential Count}

There was no significant difference in white blood cell count between PMA treated and the control groups (Figure 1) (p>0.05).

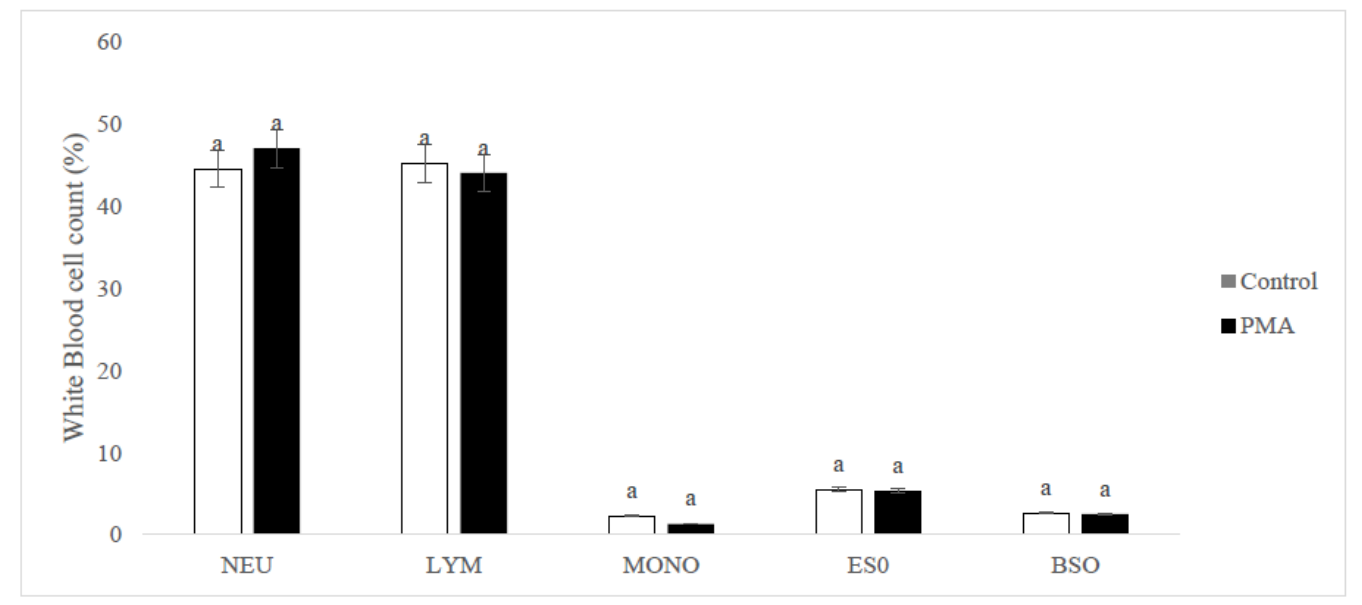

Figure 1. White blood cells count between PMA and the control groups

$\mathrm{NEU}=$ Neutrophils, $\mathrm{LYM}=$ Lymphocytes, $\mathrm{MONO}=$ Monocytes, $\mathrm{ESO}=$ Eosinophils, $\mathrm{BSO}=$ Basophils. Means with the same letters within each group are not significantly different $(\mathrm{P}<0.05)$.

\subsection{Effect of PMA on LGALS, and Galectin Binding Proteins Gene Expression in Whole Blood}

All tested LGALS -1, -2, -3, -4, -7, -8, -9, -11, -12 and the binding proteins TIM-3, LGALS3bp were expressed in blood (Figure 2). Expression levels were in the following order LGALS $-8,>-4,>-2,>-7>-3 \mathrm{bp},-1,>$ $-12,>$ TIM-3, $>-3,>-11,>-9$. Differential modulation was observed in response to PMA. Stimulation with PMA upregulated LGALS $-2,-4,-8(2.28,2.36,2.39$ folds respectively) and downregulated LGALS -9 levels (5.04 folds). The levels of LGALS $-1,-3,-7,-11,-12$, TIM-3 and 3bp remained unchanged.

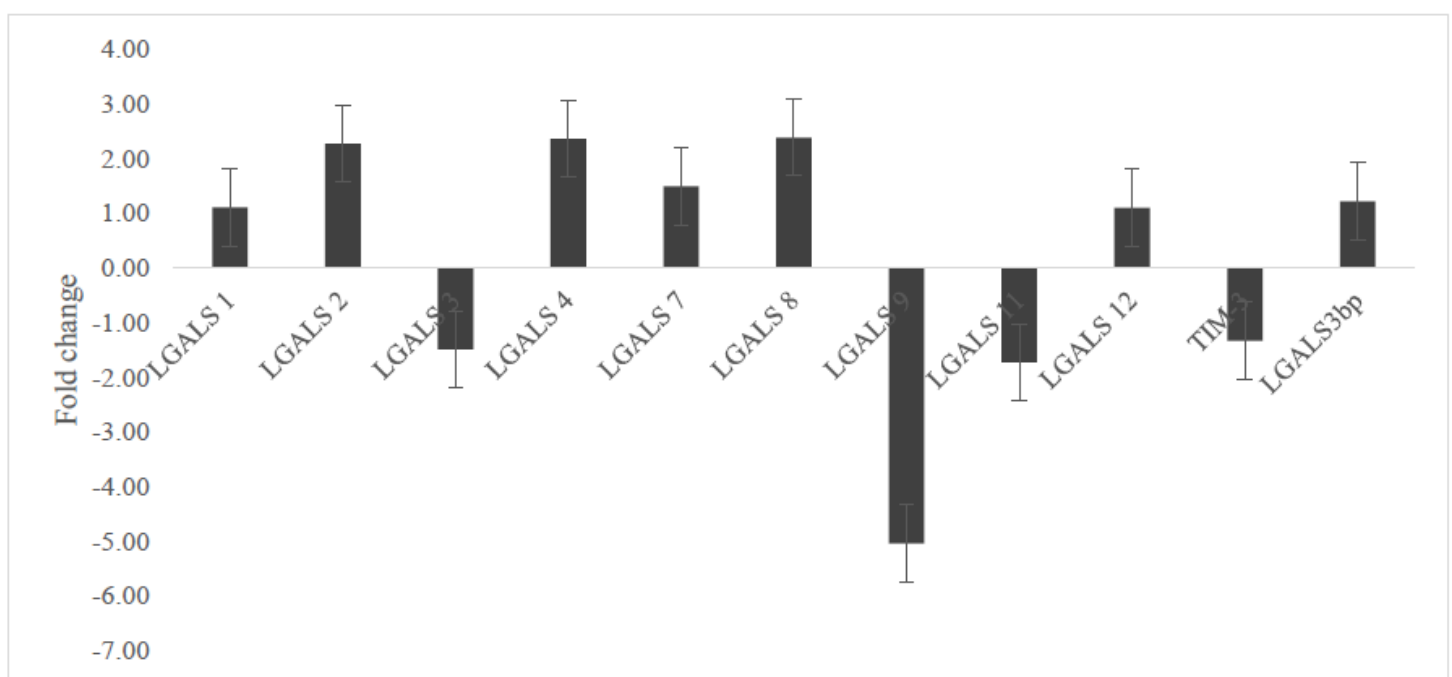

Figure 2. Fold changes in expression of LGALS -1, -2, -3, -4, -7, -8, -9, -11, -12, TIM-3 and LGALS3bp after stimulation of whole blood with PMA

(Fold change $>2$ were considered as significant).

\subsection{Effect of PMA on LGALS and Galectin Binding Proteins Gene Expression in Cow Neutrophils}

All tested LGALS $-1,-2,-3,-4,-7,-8,-9,-11,-12$ and the binding proteins TIM-3, LGALS3bp were expressed in isolated neutrophils (Figure 3). Expression levels were in the following order; TIM $-3>-7,>-2,>-4,>-12,>$ 
$-3 b p,>-8,>-9,>-1,>-3,>-11$. Differential modulation was observed in response to PMA. Stimulation with PMA upregulated transcription of LGALS $-2,-4,-7,-12$ and TIM $-3(4.10,3.80,5.29,2.99,5.55$ folds respectively) and downregulated LGALS -11 ( -2.2 folds). The levels of LGALS $-1,-3-8,-9$ and LGALS3bp remained unchanged.

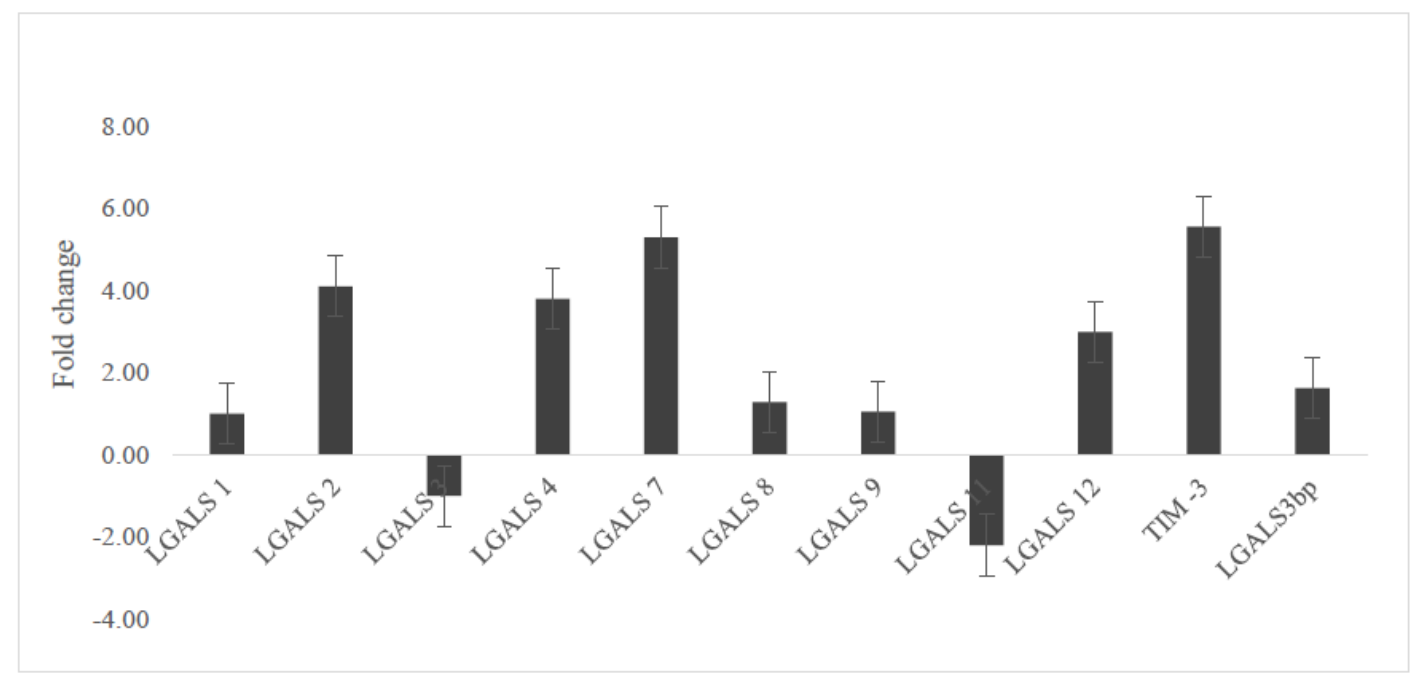

Figure 3. Fold changes in expression of LGALS -1, -2, -3, -4, -7, -8, -9, -11, -12, TIM-3 and LGALS3bp after stimulation of neutrophils with PMA

(Fold change $>2$ were considered as significant).

\subsection{Effect of PMA on Total Protein Concentration}

Total plasma protein concentration was significantly higher $(\mathrm{P}>0.05)$ in the PMA treated group compared to the control group (Figure 4A). Whereas total protein concentration in the supernatant was not significantly high in the PMA treated groups compared to the control groups (Figure 4B).
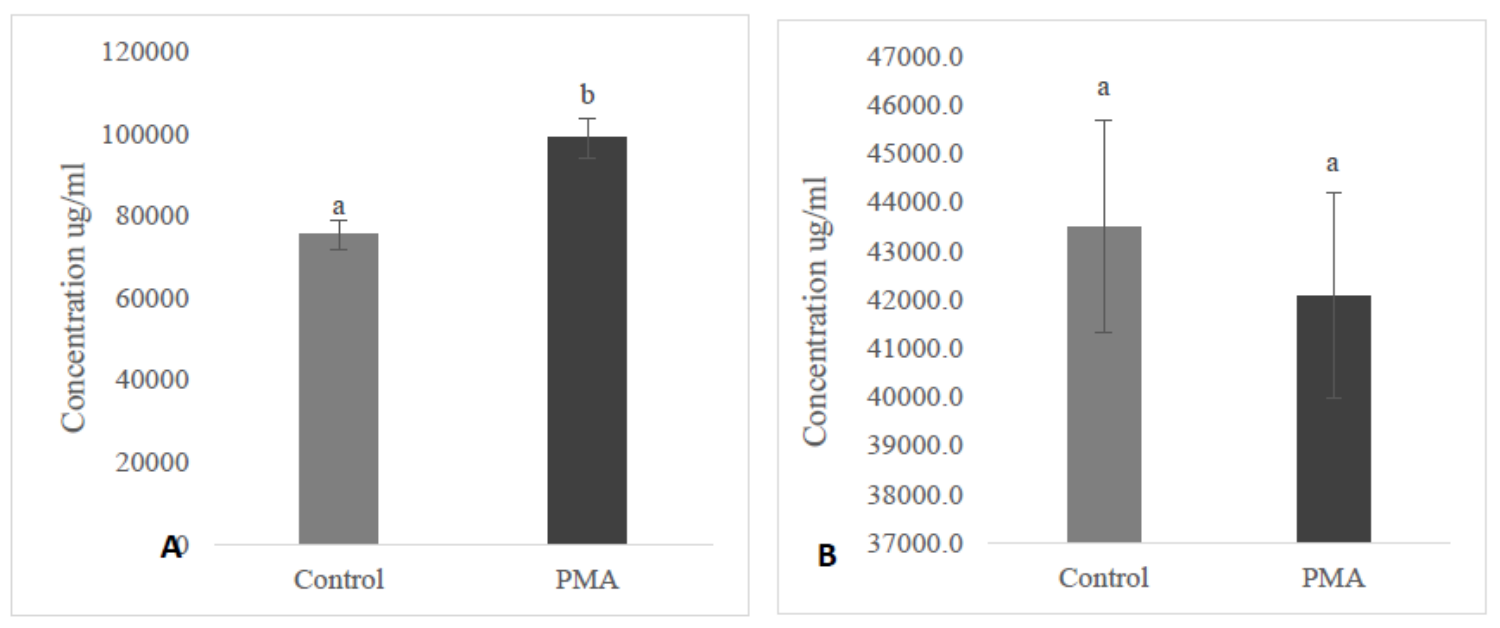

Figure 4. Average total protein concentration between control and treated groups in plasma (A) and supernatant (B). Means with the same letters are not significantly different from each other $(\mathrm{p}>0.05)$

\subsection{Effect of PMA on Galectin Secretion}

All tested GAL were secreted in plasma and supernatant. The pattern of secretion in plasma were in the following order; Gal $-9>-3,>-2,>-1,>4,>-8$. Whereas, the pattern of secretion in supernatant were in the following order; Gal $-4>-3,>-1,>-9,>2,>-8$. Stimulation with PMA decreased secretion of GAL $-2,-8,-9$, and increased GAL -1 secretion in both plasma and supernatant compared to the control groups ( $>0.05)$. In contrast, GAL -4 secretion was high $(\mathrm{p}>0.05)$ in PMA treated groups and low in PMA treated groups in plasma 
and supernatant, respectively. The secretion of GAL -3 was significantly higher in the PMA treated groups $(p<0.05)$ than the control groups in the supernatant. Whereas secretion of GAL-3 was not significantly high compared to the control groups in plasma.

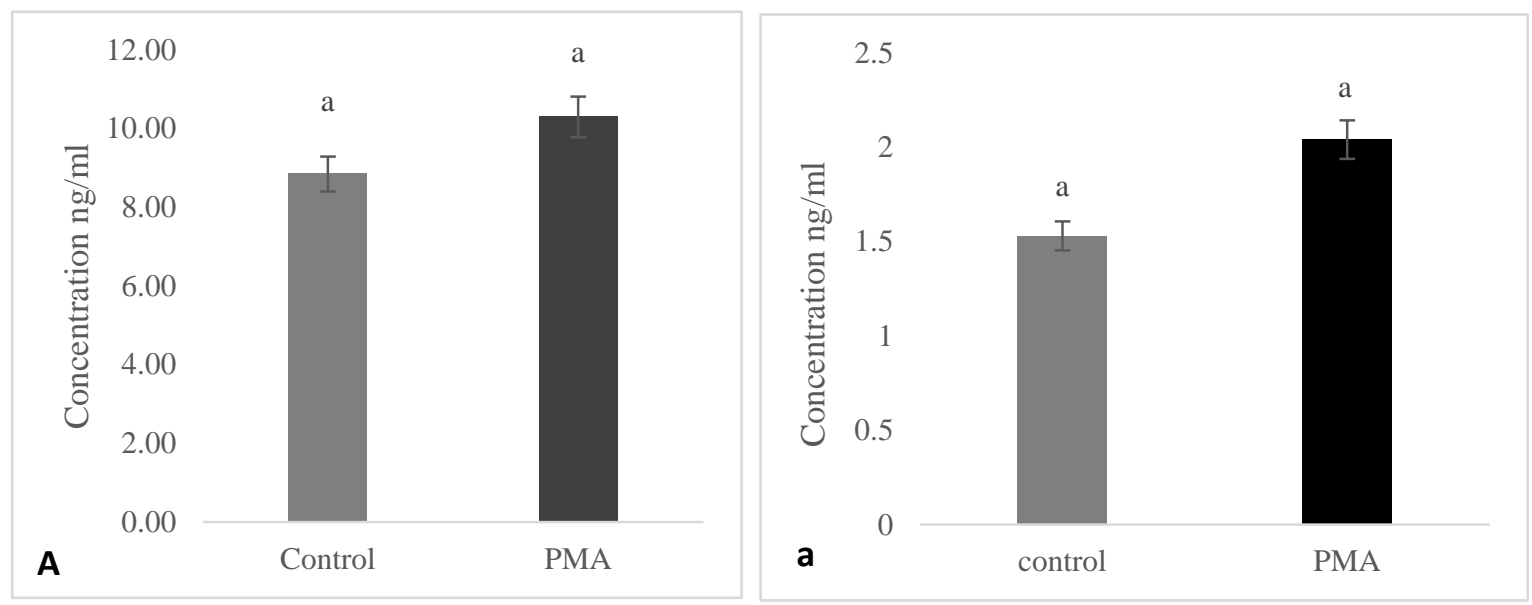
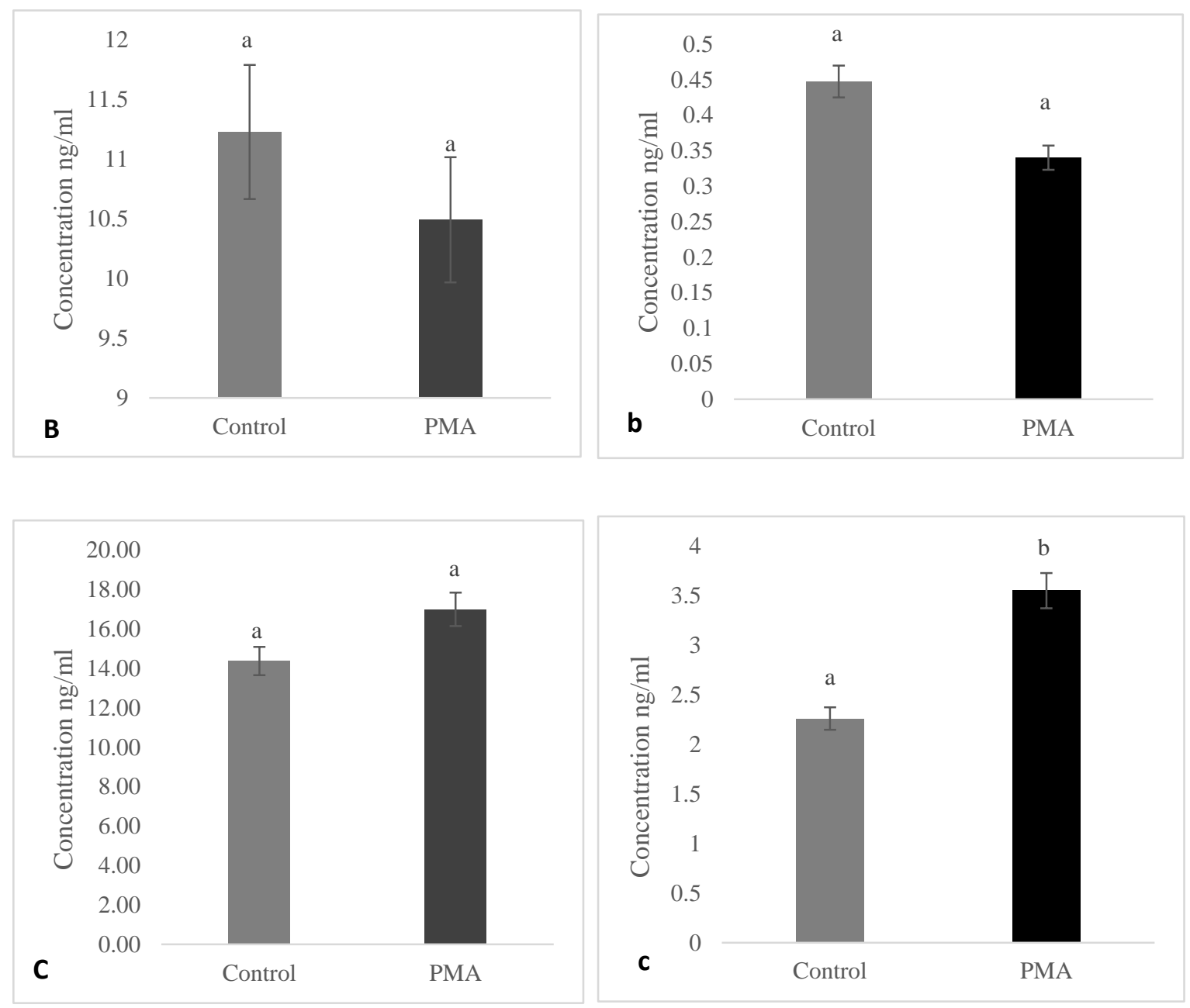

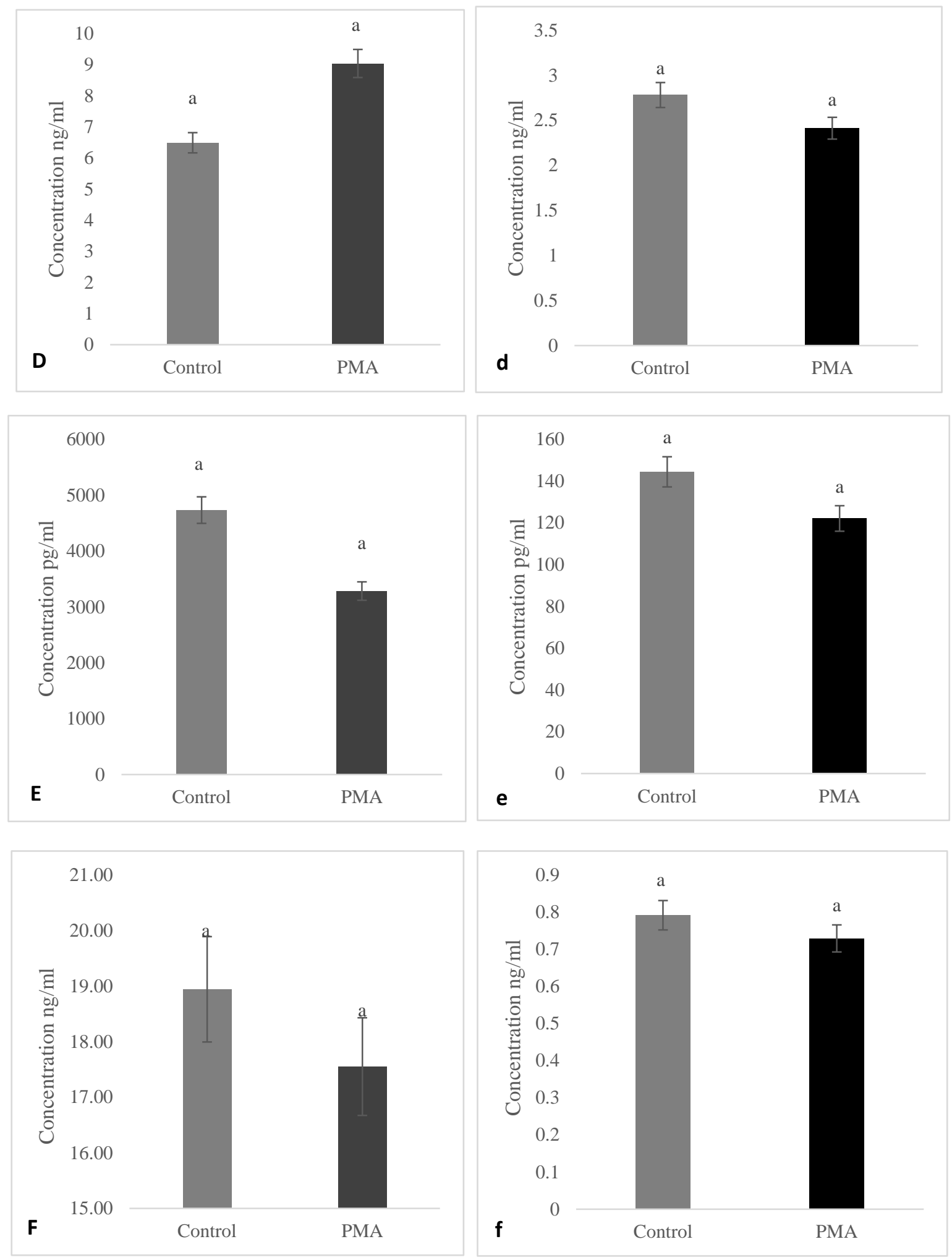

Figure 5. Average secretion of galectins in plasma (upper case) and supernatant (lower case) following PMA treatment. GAL 1 (A, a), GAL 2 (B, b), GAL 3 (C, c), GAL 4 (D, d), GAL 8 (E, e), GAL 9 (F, f). Means with different letters are significantly different from each other $(p<0.05)$

\section{Discussion}

Diverse stimuli are associated with differential and temporal modulation of gene expression in blood by immune 
cells such as neutrophils (Adjei-Fremah et al., 2016; Emmanuel K Asiamah et al., 2016; Mulumebet Worku \& Morris, 2009). Phorbol 12-myristate 13-acetate (PMA) is widely known as a protein kinase C (PKC) activator (Bae, Kim, Song, \& Kim, 2012). Activation of PKC may mediate the later induction of activation-related genes (Jain, Valge-Archer, Sinskey, \& Rao, 1992). Immune genes activation by PAMPS involves the protein kinases signaling pathways in bovine peripheral blood and neutrophils (Adjei-Fremah et al., 2018) and macrophages (Toka et al., 2019). Activation of the protein kinases pathway affects cellular activation, neutrophil NADPH-oxidase activity (Karlsson et al., 2000), and secretion of proteins such as Galectins (Madrigal-Matute et al., 2014; Zúñiga, Gruppi, Hirabayashi, Kasai, \& Rabinovich, 2001).

This study aims to discern the involvement of PKC activation on the regulation of galectin gene expression and secretion. The results of the present study demonstrated that PMA differentially modulated galectin gene expression in neutrophils and blood cells (Table 2). The expression levels of LGALS -1,-3, and 3bp in blood and neutrophils were not affected. Thus, it may suggest that the PMA signaling pathway doesn't regulate the expression of LGALS -1, -3 , and -3 bp even though they are involved in immunomodulatory activities. Previous studies have shown that GAL -2 has a distinct role, which depends on the type of cells. For instance, it acts as a proinflammatory in macrophages (Yıldırım et al., 2015) and anti-inflammatory by inducing $\mathrm{T}$ cell apoptosis (Sturm et al., 2004). Studies have shown the contradictory immune-modulatory role of GAL -4 in intestinal inflammation and cancer (Cao \& Guo, 2016).

Table 2. Summary of the effect of PMA

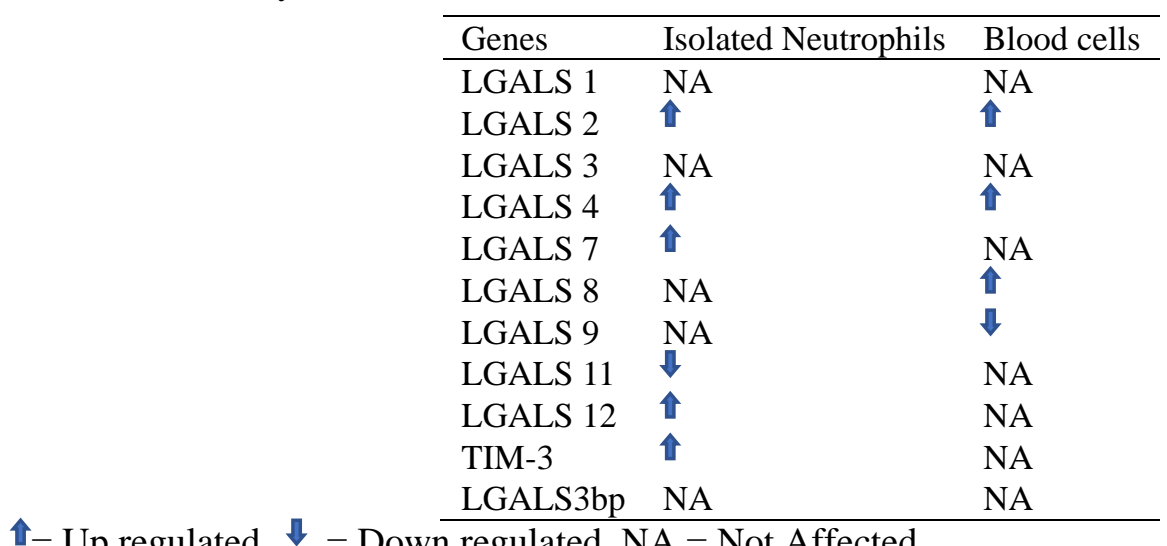

In our study, expressions of LGALS -2 and -4 were significantly up-regulated with PMA. Thus, it may suggest that the PMA modulation effect was the same on GAL -2 and -4 in neutrophils and blood cells. Further studies are needed to define the specific role in these cells, along with the mechanism by which they are regulated. The expressions of LGALS $-7,-8,-9,-11,-12$, and TIM-3 were differentially modulated in blood and neutrophils stimulated with PMA. Galectin-7 presents a unique tissue-specific expression pattern and participates in diverse biological processes (Advedissian, Deshayes, \& Viguier, 2017). In, our study LGALS 7 expression was up-regulated in the neutrophils treated group, whereas their expression levels were not affected in blood cells following PMA treatment. Thus, it may suggest GAL -7 also presents unique cell expression patterns, in which the PMA signaling pathway may regulate their unique cell-specific expression pattern. Previous studies have shown the involvement of GAL-8 in the migration or activation of inflammatory cells (Tribulatti, Cattaneo, Hellman, Mucci, \& Campetella, 2009). Further studies have shown the GAL -8 modulates the expression of immune response genes in neutrophils (Eluka-Okoludoh et al., 2019) and their migration and microbial killing function (Nishi et al., 2003). Increased expression of LGALS -8 with stimulation of PMA may indicate the activation of inflammatory cells, and the capacity of neutrophils function possibly increase.

Studies have shown the expression of GAL -9 and its binding protein TIM-3 in bovine neutrophils and further suggested modulation of the Gal9/TIM-3 signaling pathway may be of therapeutic value in periparturient dairy cows (Emmanuel Kwaku Asiamah, 2018). It has been shown that stimulation of Jurkat T cells with PMA results in the up-regulation of GAL-9 expression. However, in another study, PMA does not enhance the expression of GAL-9 mRNA in HFL-1 cells (Chabot et al., 2002). In this study, LGALS -9 expression was not significantly up-regulated, whereas their binding protein TIM-3 expression was strongly up-regulated in neutrophils after the treatment of PMA. On the other hand, TIM-3 expression was not significantly down-regulated, whereas LGALS-9 expressions were strongly down-regulated in blood cells after the treatment of PMA. Thus, it may 
suggest that the signal for galectin 9 and TIM-3 expression differs according to cell type-specific. Therefore, further work is needed to clarify the role of PKC here, as PKC is involved in many signaling pathways in the cell, and it is unknown which of these pathways would be involved in modulation of LGALS -9/TIM-3 expression. Silva et al., 2017 suggested that PKC/Tim-3-galectin-9 pathway involves a decrease in immune surveillance and the promotion of disease progression. In our study, PMA strongly modulated the expression of LGALS -9 and TIM-3 in blood and neutrophils. Therefore, Gal9/TIM-3 expression may be used as biomarkers of activation in cows.

Galectin -11 is a prototype galectin, found in epithelial cells lining the gastrointestinal tract and bile ducts and in the mucus of the abomasum and small intestines of infected animals (Hoorens et al., 2011). In this study, we observed the expression of LGALS 11 in cow blood and neutrophils. The expression of LGALS -11 in neutrophils and blood is noteworthy as it has been postulated to play important roles in protective immune responses against parasitic infection in sheep (Sakthivel et al., 2018). Therefore, the possible biological role of LGALS -11in cow blood and neutrophils needs to be explored. Galectin-12 is expressed in adipose, macrophages, and leukocytes and involves cell differential, apoptosis, and polarization (Wan, Yang, \& Liu, 2018). Studies have shown the association of expression LGALS -12 with oxidative stress (Vinnai, 2016). Further, (Yang, Hsu, Yu, Chen, \& Liu, 2004) reported the expression of LGALS-12 is upstream of the oxidative stress-sensitive ERK and Akt pathways. An increase in LGALS -12 expression in neutrophils with PMA may indicate the association of LGALS -12 expression with oxidative stress in bovine neutrophils. Further, it may be used as a biomarker of cellular stress responses. However, further analysis of LGALS -12 expression is required to draw specific and definite conclusions.

A previous study has shown that PMA stimulation regulated GAL secretion (Chabot et al., 2002). In this study, all the tested galectins were secreted. However, the pattern of galectin secretion was different in plasma and supernatant. This may be due to differential gene expression in cells. The trends of galectin were similar in blood and neutrophils except in GAL -4 secretion. Therefore, further studies are needed to specify their specific functions in these cell types.

Several studies have reported GAL -3 in cell differentiation, inflammation, fibrogenesis, and the host defense (Chen \& Kuo, 2016; Newlaczyl \& Yu, 2011). Besides, increased and decreased expression levels of galectin-3 are correlated with various types of diseases, including heart, renal, and liver disease, cancer, and infections (Dong et al., 2018). Therefore, GAL -3 may be used to diagnose and prognosis various types of disease and may also serve as a therapeutic target for treating disease (Dong et al., 2018). Furthermore, (Kusebauch et al., 2018) suggested that GAL -3 can be used as a clinical marker for cow mastitis detection. In this study, we found that the secretion of GAL-3 was significantly higher in PMA stimulated neutrophils group compared to the control group. Previously, (Madrigal-Matute et al., 2014) reported that stimulation with PMA increases GAL-3 release in human monocytes and macrophages by involving exosomes and regulated by reactive oxygen species/NADPH oxidase activity. Other studies also have shown that PMA induces neutrophil NADPH-oxidase activity (Karlsson et al., 2000) suggesting that the increase in GAL -3 secretion in PMA treated neutrophils may be due to PMA induced NADPH oxidase activity.

In conclusion, stimulation with PMA differentially modulated galectin transcription and translation in neutrophils and blood but with specific targets. The most pronounced effect of PMA was observed on LGALS-9 and TIM-3 expression and secretion of GAL -3. Thus, GAL may serve as biomarkers of cell activation with functional consequences and warrant further study.

\section{Acknowledgment}

The authors are grateful to the National Institute of Food and Agriculture Evans Allen funds: Project Molecular Signatures and Regulatory Checkpoints for Animal Health. No. NC. X 320-5-19-120.1 for funding the research.

\section{Conflict of Interests}

The authors declare that there is no conflict of interest regarding the publication of this paper.

\section{References}

Adjei-Fremah, S., Asiamah, E. K., Ekwemalor, K., Jackai, L., Schimmel, K., \& Worku, M. (2016). Modulation of bovine Wnt signaling pathway genes by cowpea phenolic extract. Journal of Agricultural Science, 8(3), 21. https://doi.org/10.5539/jas.v8n3p21

Adjei-Fremah, S., Jackai, L. E., Schimmel, K., \& Worku, M. (2018). Microarray analysis of the effect of Cowpea (Vigna unguiculata) phenolic extract in bovine peripheral blood. Journal of applied animal research, 46(1), 100-106. https://doi.org/10.1080/09712119.2016.1264305 
Adjei-Fremah, S., \& Worku, M. (2019). Cowpea polyphenol extract regulates galectin gene expression in bovine blood. Animal biotechnology, 1-12. https://doi.org/10.1080/10495398.2019.1640234

Advedissian, T., Deshayes, F., \& Viguier, M. (2017). Galectin-7 in epithelial homeostasis and carcinomas. International journal of molecular sciences, 18(12), 2760. https://doi.org/10.3390/ijms18122760

Asiamah, E., Adjei-Fremah, S., Ekwemalor, K., Osei, B., Ismail, H., \& Worku, M. (2017). The effect of stage of lactation and parturition on galectin expression in cow blood. Journal of animal science, 95, 167. https://doi.org/10.2527/asasann.2017.338

Asiamah, E., Adjei-Fremah, S., Ekwemalor, K., Sordillo, L., \& Worku, M. (2018). Parity and periparturient period affects galectin gene expression in Holstein cow blood. J Appl Biotechn, 6, 20. https://doi.org/10.5296/jab.v6i2.13017

Asiamah, E. K. (2018). Galectin Gene Expression and Secretion in Dairy Cow Blood. North Carolina Agricultural and Technical State University.

Asiamah, E. K., Adjei-Fremah, S., Osei, B., Ekwemalor, K., \& Worku, M. (2016). An extract of Sericea Lespedeza modulates production of inflammatory markers in pathogen associated molecular pattern (PAMP) activated ruminant blood. Journal of Agricultural Science, 8(9), 1. https://doi.org/10.5539/jas.v8n9p1

Asiamah, E. K., Ekwemalor, K., Adjei-Fremah, S., Osei, B., Newman, R., \& Worku, M. (2019). Natural and synthetic pathogen associated molecular patterns modulate galectin expression in cow blood. Journal of animal science and technology, 61(5), 245. https://doi.org/10.5187/jast.2019.61.5.245

Bae, C. H., Kim, H. S., Song, S.-Y., \& Kim, Y.-D. (2012). Phorbol 12-myristate 13-acetate induces MUC16 expression via $\mathrm{PKC} \delta$ and $\mathrm{p} 38$ in human airway epithelial cells. Clinical and experimental otorhinolaryngology, 5(3), 161. https://doi.org/10.3342/ceo.2012.5.3.161

Boissonneault, K. R., Henningsen, B. M., Bates, S. S., Robertson, D. L., Milton, S., Pelletier, J., ... Housman, D. E. (2013). Gene expression studies for the analysis of domoic acid production in the marine diatom Pseudo-nitzschia multiseries. BMC molecular biology, 14(1), 25. https://doi.org/10.1186/1471-2199-14-25

Brown, G. B., \& Roth, J. A. (1991). Comparison of the response of bovine and human neutrophils to various stimuli. Veterinary immunology and immunopathology, 28(3-4), 201-218. https://doi.org/10.1016/0165-2427(91)90115-S

Brym, P., Ruść, A., \& Kamiński, S. (2013). Evaluation of reference genes for qRT-PCR gene expression studies in whole blood samples from healthy and leukemia-virus infected cattle. Veterinary immunology and immunopathology, 153(3-4), 302-307. https://doi.org/10.1016/j.vetimm.2013.03.004

Cao, Z.-Q., \& Guo, X.-L. (2016). The role of galectin-4 in physiology and diseases. Protein \& cell, 7(5), 314-324. https://doi.org/10.1007/s13238-016-0262-9

Chabot, S., Kashio, Y., Seki, M., Shirato, Y., Nakamura, K., Nishi, N., ... Hirashima, M. (2002). Regulation of galectin-9 expression and release in Jurkat T cell line cells. Glycobiology, 12(2), 111-118. https://doi.org/10.1093/glycob/12.2.111

Chen, S.-C., \& Kuo, P.-L. (2016). The role of galectin-3 in the kidneys. International journal of molecular sciences, 17(4), 565. https://doi.org/10.3390/ijms 17040565

Dong, R., Zhang, M., Hu, Q., Zheng, S., Soh, A., Zheng, Y., \& Yuan, H. (2018). Galectin-3 as a novel biomarker for disease diagnosis and a target for therapy. International journal of molecular medicine, 41(2), 599-614. https://doi.org/10.3892/ijmm.2017.3311

Eluka-Okoludoh, E., Ekwemalor, K., Mulakala, B., Adjei-Fremah, S., \& Worku, M. (2019). Galectin-8 modulates innate and adaptive immune response genes in bovine neutrophils. J Mol Biol Res, 9(1), 24-32. https://doi.org/10.5539/jmbr.v9n1p24

Hoorens, P. R., Rinaldi, M., Li, R. W., Goddeeris, B., Claerebout, E., Vercruysse, J., \& Geldhof, P. (2011). Genome wide analysis of the bovine mucin genes and their gastrointestinal transcription profile. BMC genomics, 12(1), 140. https://doi.org/10.1186/1471-2164-12-140

Jain, J., Valge-Archer, V., Sinskey, A., \& Rao, A. (1992). The AP-1 site at-150 bp, but not the NF-kappa B site, is likely to represent the major target of protein kinase $\mathrm{C}$ in the interleukin 2 promoter. The Journal of experimental medicine, 175(3), 853-862. https://doi.org/10.1084/jem.175.3.853

Jarczak, J., Kaba, J., \& Bagnicka, E. (2014). The validation of housekeeping genes as a reference in quantitative 
Real Time PCR analysis: application in the milk somatic cells and frozen whole blood of goats infected with caprine arthritis encephalitis virus. Gene, 549(2), 280-285. https://doi.org/10.1016/j.gene.2014.07.063

Karlsson, A., Nixon, J. B., \& McPhail, L. C. (2000). Phorbol myristate acetate induces neutrophil NADPH-oxidase activity by two separate signal transduction pathways: dependent or independent of phosphatidylinositol 3-kinase. Journal of leukocyte biology, 67(3), 396-404. https://doi.org/10.1002/jlb.67.3.396

Kim, K., Mayer, E. P., \& Nachtigal, M. (2003). Galectin-3 expression in macrophages is signaled by Ras/MAP kinase pathway and up-regulated by modified lipoproteins. Biochimica et Biophysica Acta (BBA)-Molecular Cell Research, 1641(1), 13-23. https://doi.org/10.1016/S0167-4889(03)00045-4

Kusebauch, U., Hernández-Castellano, L. E., Bislev, S. L., Moritz, R. L., Røntved, C. M., \& Bendixen, E. (2018). Selected reaction monitoring mass spectrometry of mastitis milk reveals pathogen-specific regulation of bovine host response proteins. Journal of Dairy Science, 101(7), 6532-6541.

https://doi.org/10.3168/jds.2017-14312

Laderach, D. J., Gentilini, L. D., Giribaldi, L., Delgado, V. C., Nugnes, L., Croci, D. O., ... Mazza, O. (2012). A unique galectin signature in human prostate cancer progression suggests galectin-1 as a key target for treatment of advanced disease. Cancer research. https://doi.org/10.1158/0008-5472.CAN-12-1260

Livak, K. J., \& Schmittgen, T. D. (2001). Analysis of relative gene expression data using real-time quantitative PCR and the 2- $\Delta \Delta$ CT method. Methods, 25(4), 402-408. https://doi.org/10.1006/meth.2001.1262

Madrigal-Matute, J., Lindholt, J. S., Fernandez-Garcia, C. E., Benito-Martin, A., Burillo, E., Zalba, G., ... Egido, J. (2014). Galectin-3, a biomarker linking oxidative stress and inflammation with the clinical outcomes of patients with atherothrombosis. Journal of the American Heart Association, 3(4), e000785. https://doi.org/10.1161/JAHA.114.000785

Medzhitov, R., \& Janeway Jr, C. (2000). Innate immunity. New England Journal of Medicine, 343(5), 338-344. https://doi.org/10.1056/NEJM200008033430506

Modenutti, C. P., Capurro, J. I. B., Di Lella, S., \& Martí, M. A. (2019). The Structural Biology of Galectin-Ligand Recognition: Current Advances in Modeling Tools, Protein Engineering, and Inhibitor Design. Frontiers in Chemistry, 7. https://doi.org/10.3389/fchem.2019.00823

Newlaczyl, A. U., \& Yu, L.-G. (2011). Galectin-3-a jack-of-all-trades in cancer. Cancer letters, 313(2), 123-128. https://doi.org/10.1016/j.canlet.2011.09.003

Nio-Kobayashi, J. (2017). Tissue-and cell-specific localization of galectins, $\beta$-galactose-binding animal lectins, and their potential functions in health and disease. Anatomical science international, 92(1), 25-36. https://doi.org/10.1007/s12565-016-0366-6

Nishi, N., Shoji, H., Seki, M., Itoh, A., Miyanaka, H., Yuube, K., ... Nakamura, T. (2003). Galectin-8 modulates neutrophil function via interaction with integrin $\alpha \mathrm{M}$. Glycobiology, 13(11), 755-763. https://doi.org/10.1093/glycob/cwg102

Paape, M., Mehrzad, J., Zhao, X., Detilleux, J., \& Burvenich, C. (2002). Defense of the bovine mammary gland by polymorphonuclear neutrophil leukocytes. Journal of mammary gland biology and neoplasia, 7(2), 109-121. https://doi.org/10.1023/A:1020343717817

Popa, S. J., Stewart, S. E., \& Moreau, K. (2018). Unconventional secretion of annexins and galectins. Paper presented at the Seminars in cell \& developmental biology. https://doi.org/10.1016/j.semcdb.2018.02.022

Robinson, B. S., Arthur, C. M., Evavold, B., Roback, E., Kamili, N. A., Stowell, C. S., ... Cummings, R. D. (2019). The sweet-side of leukocytes: galectins as master regulators of neutrophil function. Frontiers in immunology, 10. https://doi.org/10.3389/fimmu.2019.01762

Sakthivel, D., Swan, J., Preston, S., Shakif-Azam, M., Faou, P., Jiao, Y., ... Piedrafita, D. (2018). Proteomic identification of galectin-11 and 14 ligands from Haemonchus contortus. PeerJ, 6, e4510. https://doi.org/10.7717/peerj.4510

Sato, S., St-Pierre, C., Bhaumik, P., \& Nieminen, J. (2009). Galectins in innate immunity: dual functions of host soluble $\beta$-galactoside-binding lectins as damage-associated molecular patterns (DAMPs) and as receptors for pathogen-associated molecular patterns (PAMPs). Immunological reviews, 230(1), 172-187. https://doi.org/10.1111/j.1600-065X.2009.00790.x

Stowell, S. R., Qian, Y., Karmakar, S., Koyama, N. S., Dias-Baruffi, M., Leffler, H., ... Cummings, R. D. (2008). 
Differential roles of galectin-1 and galectin-3 in regulating leukocyte viability and cytokine secretion. The Journal of Immunology, 180(5), 3091-3102. https://doi.org/10.4049/jimmunol.180.5.3091

Sturm, A., Lensch, M., André, S., Kaltner, H., Wiedenmann, B., Rosewicz, S., ... Gabius, H.-J. (2004). Human galectin-2: novel inducer of $\mathrm{T}$ cell apoptosis with distinct profile of caspase activation. The Journal of Immunology, 173(6), 3825-3837. https://doi.org/10.4049/jimmunol.173.6.3825

Sundqvist, M., Welin, A., Elmwall, J., Osla, V., Nilsson, U. J., Leffler, H., ... Karlsson, A. (2018). Galectin-3 type-C self-association on neutrophil surfaces. The carbohydrate recognition domain regulates cell function. Journal of leukocyte biology, 103(2), 341-353. https://doi.org/10.1002/JLB.3A0317-110R

Toka, F. N., Dunaway, K., Smaltz, F., Szulc-Dąbrowska, L., Drnevich, J., Mielcarska, M. B., ... Schweizer, M. (2019). Bacterial and viral pathogen-associated molecular patterns induce divergent early transcriptomic landscapes in a bovine macrophage cell line. BMC genomics, $20(1), 15$. https://doi.org/10.1186/s12864-018-5411-5

Tribulatti, M. V., Cattaneo, V., Hellman, U., Mucci, J., \& Campetella, O. (2009). Galectin-8 provides costimulatory and proliferative signals to T lymphocytes. Journal of leukocyte biology, 86(2), 371-380. https://doi.org/10.1189/jlb.0908529

Van Kooyk, Y., \& Rabinovich, G. A. (2008). Protein-glycan interactions in the control of innate and adaptive immune responses. Nature immunology, 9(6), 593-601. https://doi.org/10.1038/ni.f.203

Vega-Carrascal, I., Bergin, D. A., McElvaney, O. J., McCarthy, C., Banville, N., Pohl, K., ... McElvaney, N. G. (2014). Galectin-9 signaling through TIM-3 is involved in neutrophil-mediated Gram-negative bacterial killing: an effect abrogated within the cystic fibrosis lung. The Journal of Immunology, 192(5), 2418-2431. https://doi.org/10.4049/jimmunol.1300711

Vinnai, J. R. (2016). The Association Between Oxidative Stress, Cellular Differentiation And Galectins In Human Promyelocytic Leukemia Cells (HL-60). https://doi.org/10.1016/j.yexcr.2017.03.059

Wan, L., Yang, R.-Y., \& Liu, F.-T. (2018). Galectin-12 in cellular differentiation, apoptosis and polarization. International journal of molecular sciences, 19(1), 176. https://doi.org/10.3390/ijms19010176

Worku, M., Asiamah, E. K., Vailati-Riboni, M., Loor, J. J., \& Kang, H. W. (2020). Supplemental Methionine, Choline, or Taurine Affect Galectin Gene Expression in Adult Holstein Cow And Neonatal Holstein Calf Neutrophils in Vitro. Journal of microbiology, biotechnology and food sciences, 10(1), 87-92. https://doi.org/10.15414/jmbfs.2020.10.1.87-92

Worku, M., Ekwemalor, K., Asiamah, E., Adjei-Fremah, S., Osei, B., Mulakala, B., ... Ismail, H. (2018). Expression and Secretion of circulating galectins in domestic ruminants. Journal of animal science, 96, 29-30. https://doi.org/10.1093/jas/sky404.067

Worku, M., \& Morris, A. (2009). Binding of different forms of lipopolysaccharide and gene expression in bovine blood neutrophils. Journal of Dairy Science, 92(7), 3185-3193. https://doi.org/10.3168/jds.2008-1905

Yang, R.-Y., Hsu, D. K., Yu, L., Chen, H.-Y., \& Liu, F.-T. (2004). Galectin-12 is required for adipogenic signaling and adipocyte differentiation. Journal of Biological Chemistry, 279(28), 29761-29766. https://doi.org/10.1074/jbc.M401303200

Yıldırım, C., Vogel, D. Y., Hollander, M. R., Baggen, J. M., Fontijn, R. D., Nieuwenhuis, S., ... Garcia-Vallejo, J. J. (2015). Galectin-2 induces a proinflammatory, anti-arteriogenic phenotype in monocytes and macrophages. PLoS One, 10(4), e0124347. https://doi.org/10.1371/journal.pone.0124347

Young, A. R., Barcham, G. J., McWilliam, H. E., Piedrafita, D. M., \& Meeusen, E. N. (2012). Galectin secretion and binding to adult Fasciola hepatica during chronic liver fluke infection of sheep. Veterinary immunology and immunopathology, 145(1-2), 362-367. https://doi.org/10.1016/j.vetimm.2011.12.010

Zúñiga, E., Gruppi, A., Hirabayashi, J., Kasai, K. I., \& Rabinovich, G. A. (2001). Regulated Expression and Effect of Galectin-1 onTrypanosoma cruzi-Infected Macrophages: Modulation of Microbicidal Activity and Survival. Infection and immunity, 69(11), 6804-6812. https://doi.org/10.1128/IAI.69.11.6804-6812.2001

\section{Copyrights}

Copyright for this article is retained by the author(s), with first publication rights granted to the journal.

This is an open-access article distributed under the terms and conditions of the Creative Commons Attribution license (http://creativecommons.org/licenses/by/4.0/). 